\title{
Short-term outcomes of robotic- versus laparoscopic-assisted Total Gastrectomy for advanced gastric Cancer: a propensity score matching study
}

Changdong Yang ${ }^{\dagger}$, Yan Shi ${ }^{\dagger}$, Shaohui Xie, Jun Chen, Yongliang Zhao, Feng Qian, Yingxue Hao, Bo Tang and Peiwu Yu (iD

\begin{abstract}
Background: Few studies have been designed to evaluate the short-term outcomes between robotic-assisted total gastrectomy (RATG) and laparoscopy-assisted total gastrectomy (LATG) for advanced gastric cancer (AGC). The purpose of this study was to assess the short-term outcomes of RATG compared with LATG for AGC.

Methods: We retrospectively evaluated 126 and 257 patients who underwent RATG or LATG, respectively. In addition, we performed propensity score matching (PSM) analysis between RATG and LATG for clinicopathological characteristics to reduce bias and compared short-term surgical outcomes.

Results: After PSM, the RATG group had a longer mean operation time $(291.14 \pm 59.18$ vs. $270.34 \pm 52.22 \mathrm{~min}, p=$ 0.003), less intraoperative bleeding (154.37 \pm 89.68 vs. $183.77 \pm 95.39 \mathrm{ml}, p=0.004)$ and more N2 tier RLNs $(9.07 \pm$ 5.34 vs. $7.56 \pm 4.50, p=0.016)$ than the LATG group. Additionally, the total RLNs of the RATG group were almost significantly different compared to that of the LATG group (34.90 \pm 13.05 vs. $31.91 \pm 12.46, p=0.065)$. Moreover, no significant differences were found between the two groups in terms of the length of incision, proximal resection margin, distal resection margin, residual disease and postoperative hospital stay. There was no significant difference in the overall complication rate between the RATG and LATG groups after PSM (23.8\% vs. 28.6\%, $p=0.390)$. Grade II complications accounted for most of the complications in the two cohorts after PSM. The conversion rates were 4.55 and $8.54 \%$ in the RATG and LATG groups, respectively, with no significant difference $(p=0.145)$, and the ratio of splenectomy were 1.59 and $0.39 \%(p=0.253)$. The mortality rates were 0.8 and $0.4 \%$ for the RATG and LATG groups, respectively $(p=1.000)$.
\end{abstract}

Conclusion: This study demonstrates that RATG is comparable to LATG in terms of short-term surgical outcomes. Keywords: Advanced gastric cancer, Total gastrectomy, Robotic, Laparoscopic, Short-term outcomes

\footnotetext{
* Correspondence: yupeiwu01@sina.com

${ }^{\dagger}$ Changdong Yang and Yan Shi contributed equally to this work and should be considered co-first authors.

Department of General Surgery, Southwest Hospital, Army Medical University,

30 Gaotanyan Street, Shapingba District 400038, Chongqing, China
}

(C) The Author(s). 2020 Open Access This article is licensed under a Creative Commons Attribution 4.0 International License, which permits use, sharing, adaptation, distribution and reproduction in any medium or format, as long as you give appropriate credit to the original author(s) and the source, provide a link to the Creative Commons licence, and indicate if changes were made. The images or other third party material in this article are included in the article's Creative Commons licence, unless indicated otherwise in a credit line to the material. If material is not included in the article's Creative Commons licence and your intended use is not permitted by statutory regulation or exceeds the permitted use, you will need to obtain permission directly from the copyright holder. To view a copy of this licence, visit http://creativecommons.org/licenses/by/4.0/. The Creative Commons Public Domain Dedication waiver (http://creativecommons.org/publicdomain/zero/1.0/) applies to the data made available in this article, unless otherwise stated in a credit line to the data. 


\section{Background}

Gastric cancer (GC) is the fifth most common cancer and the third leading cause of cancer-related death worldwide [1]. Its incidence and mortality rates have been steadily declining worldwide since the middle of the 20th century [2, 3]. However, it is notable that the morbidity of esophagogastric junction cancer is increasing in Western and Eastern countries [2-5]. Total gastrectomy (TG) with adequate regional lymphadenectomy is the most common treatment choice for upper GC and includes cancers located in the proximal third of the stomach and esophagogastric junction (EGJ) (Siewert type II and III) or cancers located at the lower two-thirds of the stomach to ensure a tumour-free surgical margin [6-8]. Since Kitano [9] reported laparoscopy-assisted distal gastrectomy in 1994 for the first time, laparoscopy-assisted gastrectomy has been widely used for gastric cancer [10-12]. Despite its technical difficulty, laparoscopy-assisted total gastrectomy (LATG) has been shown to be technically feasible and is superior to open total gastrectomy performed by experienced surgeons in terms of its safety and shortterm outcomes $[13,14]$. However, the two-dimensional visualization and limited movement of laparoscopic instruments make it difficult to perform lymphadenectomy precisely. Robotic surgical system overcomes those limitations including eliminating the traces of physiologic human tremor and increasing dexterity through its typical internal articulated endoscopic wrist (EndoWrist ${ }^{\text {тм }}$ System) for a precise lymphadenectomy with a 3D highresolution images at the console [15]. In 2002, Hashizume reported robotic-assisted gastrectomy for the first time [16]. Since then, robotic surgery has been demonstrated to obtain similar or even better anatomical and operative conditions compared to the traditional laparoscopic approach during gastric resection [15, 17-21]. However, most of the reported cases were early gastric cancer (EGC) [22, 23], and few studies have retrospectively compared robotic-assisted total gastrectomy (RATG) with LATG for advanced gastric cancer (AGC) $[15,24]$. The aim of this study is to evaluate the feasibility and safety of RATG and LATG for AGC using the propensity score matching (PSM) method.

\section{Methods}

\section{Patients}

Patients diagnosed with GC by means of gastroscopy, biopsy and histopathological assessment who underwent total gastrectomy were screened from the prospectively maintained gastric cancer database at the Department of General Surgery, Southwest Hospital, Army Medical University from March 2010 to December 2017. Data from 573 consecutive patients who underwent RATG or LATG for gastric cancer were collected. The inclusion criteria of the study were defined as follows: (1) age between 18 and 80 years old; (2) no preoperative chemotherapy or radiation therapy performed before surgery; (3) depth of invasion confined to pT2, pT3, or pT4a; (4) no distant metastasis or invasion to adjacent organs; (5) receiving LATG or RATG with D2 lymphadenectomy. Patients who underwent RATG were matched to those who underwent LATG at a 1:1 ratio by using a propensity score matching (PSM) method to reduce the effect of bias due to the imbalanced clinicopathological features of the two groups. The matched variables included age, sex, body mass index (BMI), American Society of Anesthesiologists (ASA) grade, $\mathrm{T}$ stage, $\mathrm{N}$ stage, tumour-node-metastasis classification (TNM), tumour size, tumour location, Borrmann type, differentiation and comorbidities. Postoperative complications were recorded and classified according to the ClavienDindo classification system [25, 26]. Pathological and clinical staging were determined based on the AJCC Cancer Staging Manual (Eighth Edition) [27].

\section{Operation procedures}

All patients underwent standard radical total gastrectomy with D2 lymphadenectomy according to the Guidelines of the Japanese Gastric Cancer Association [7, 28]. The da Vinci Surgical System (Intuitive Surgical, Inc., Sunnyvale, CA) was used as the robotic tool for all patients in the robotic group. During RATG, five surgical ports were inserted in the upper abdomen as we previously described [17]. The details of the gastrectomy and lymph node dissections during the RATG procedures did not differ from those during the LATG procedures except for the use of the articulating robotic instruments. After finishing the lymph node (LN) dissection, the robotic arms were undocked and withdrawn. We conducted Roux-en-Y reconstruction to rebuild the digestive tract in both the RATG and LATG surgeries, mostly through a $6-8 \mathrm{~cm}$ upper abdominal incision, as we previously described [17]. When conducting the esophagojejunostomy, the esophagus was transected with an anvil in it, and then the Roux-en-Y limb was brought up to complete an esophagojejunostomy using a 25-mm circular stapler, while the jejunal stump was closed and side-to-side jejunojejunostomy was established using an endoscopic linear stapler [17]. The decision to reinforce the anastomoses or the duodenal stump depended on the operators' judgement during surgeries, and two drainage tubes were placed under the liver and beside the spleen. All patients were informed of the advantages and disadvantages of RATG and LATG, and an informed consent form was signed before surgery by the patients themselves or their legal representatives. The surgeries were performed by five experienced surgeons who received robotic surgery 
certification and had performed robotic surgery (RG) with D2 lymphadenectomy in more than 30 cases. RATG and LATG were compared by evaluating the surgical performance and postoperative short-term clinical outcomes, including the operation time, estimated blood loss, proximal resection margin, distal resection margin, number of retrieved lymph nodes (RLNs), postoperative complications and length of postoperative hospital stay.

\section{Statistical analysis}

SPSS version 22.0 for Windows (IBM Corp., Armonk, NY) was used for statistical analysis. R version 3.5.2 for Windows was used for PSM by using the MatchIt package. The independent sample $t$ test, Mann-Whitney test and chi-square test were used for continuous variables or categorical variables. Continuous variables are presented as the mean \pm standard deviation (SD). A value of $p<0.05$ was considered statistically significant, and all $p$ values were two-sided.

\section{Results}

\section{Clinicopathological characteristics}

A total of 160 patients were excluded for the following reasons: patients were over 80 years old $(n=3)$, had early gastric cancer $(n=33)$, received palliative surgery $(n=$ $75)$, received neoadjuvant chemotherapy before surgery $(n=21)$, underwent combined organ resection $(n=23)$, underwent D2+ lymphadenectomy $(n=5)$. The statistical analyses were performed in the remaining 413 patients undergoing radical total gastrectomy, of whom 132 underwent RATG and 281 underwent LATG (Fig. 1). Finally, the study cohort comprised 126 patients who underwent RATG and 126 matched LATG patients after PSM. The patients' clinicopathological characteristics before and after PSM are summarized in Table 1. The patients in the two groups before PSM were generally matched with no significant differences $(p>0.05)$ in age, sex, BMI, ASA grade, Borrmann type, $\mathrm{N}$ stage, TNM stage, or medical comorbidities (such as diabetes, hypertension, heart disease and contagious disease), except $\mathrm{T}$ stage, tumour differentiation and abdominal surgery history $(p<0.05)$. However, those biases were reduced after PSM, and the clinicopathological characteristics were better matched between the two groups.

\section{Short-term surgical outcomes of the cohorts}

The postoperative clinical outcomes before and after PSM are detailed in Table 2. Before PSM, the RATG group had a longer mean operation time $(291.14 \pm 59.18$ vs. $270.27 \pm 49.41 \mathrm{~min}, \quad p=0.003)$, less intraoperative bleeding (154.37 \pm 89.68 vs. $175.19 \pm 105.44 \mathrm{ml}, \quad p=$ $0.028)$, more total RLNs $(34.90 \pm 13.05$ vs. $32.02 \pm 12.41$, $p=0.037)$, and more $\mathrm{N} 2$ tier RLNs $(9.07 \pm 5.34$ vs.
7.61 $\pm 4.57, p=0.007)$ than the LATG group. After PSM, the RATG group still had a longer mean operation time $(291.14 \pm 59.18$ vs. $270.34 \pm 52.22 \mathrm{~min}, p=0.003)$, less intraoperative bleeding $(154.37 \pm 89.68$ vs. $183.77 \pm 95.39$ $\mathrm{ml}, p=0.004)$ and more N2 tier RLNs $(9.07 \pm 5.34$ vs. $7.56 \pm 4.50, p=0.016)$ than the LATG group. Additionally, the total RLNs of the RATG group were almost significantly different compared to that of the LATG group $(34.90 \pm 13.05$ vs. $31.91 \pm 12.46, p=0.065)$. Moreover, no significant differences were found between the two groups in terms of the length of incision, proximal resection margin, distal resection margin, residual disease and postoperative hospital stay.

Six patients underwent conversion to laparotomy in the robotic group and 24 in the laparoscopic group ( $4.55 \%$ vs. $8.54 \%, p=0.145)$. In the robotic group, 2 patients encountered uncontrollable bleeding, 2 caused by tight adhesion and 2 had the left gastric artery surrounded by lymph nodes. In the laparoscopic group, 13 patients had tight adhesion, 4 had the left gastric artery surrounded by lymph nodes, 2 caused by enlarged lymph nodes, 1 caused by the tumour surrounding the artery, 2 caused by a giant tumour, 1 encountered bleeding of a short gastric vessel, and 1 encountered mechanical failure of the stapler. Furthermore, two patients underwent splenectomy in the robotic group, and one underwent splenectomy in the laparoscopic group because of the tight adhesion of the spleen hilum (1.59\% vs. $0.39 \%, p=0.253)$.

The postoperative complications before and after PSM are shown in Table 3. There was no significant difference in the overall complication rate between the RATG and LATG groups before PSM (23.8\% vs. $29.2 \%$, $p=0.268)$ and after PSM (23.8\% vs. $28.6 \%, p=0.390)$. Grade II complications accounted for most of the complications in the two cohorts both before and after PSM. Moreover, no significant differences were noted in the major complications (Clavien-Dindo grade $\geq$ IIIa) among all complications between the two cohorts before PSM (5.6\% vs. $8.2 \%, p=0.356)$ and after PSM (5.6\% vs. $5.6 \%, p=1.000)$. One patient in the RATG died of MODS after anastomotic leakage who received a second surgical procedure. One patient in the LATG died of MODS after pulmonary failure. The mortality rates were 0.8 and $0.4 \%$ for the RATG and LATG groups, respectively $(p=1.000)$.

\section{Stratified analysis of different related factors}

We evaluated the surgical outcomes of the patients according to different related factors, including tumour location, tumour size and age. The surgical outcomes of subgroup analyses are summarized in Tables 4-6. Subgroup analysis of tumour location (Table 4) suggested that the RATG group had less blood loss than the 


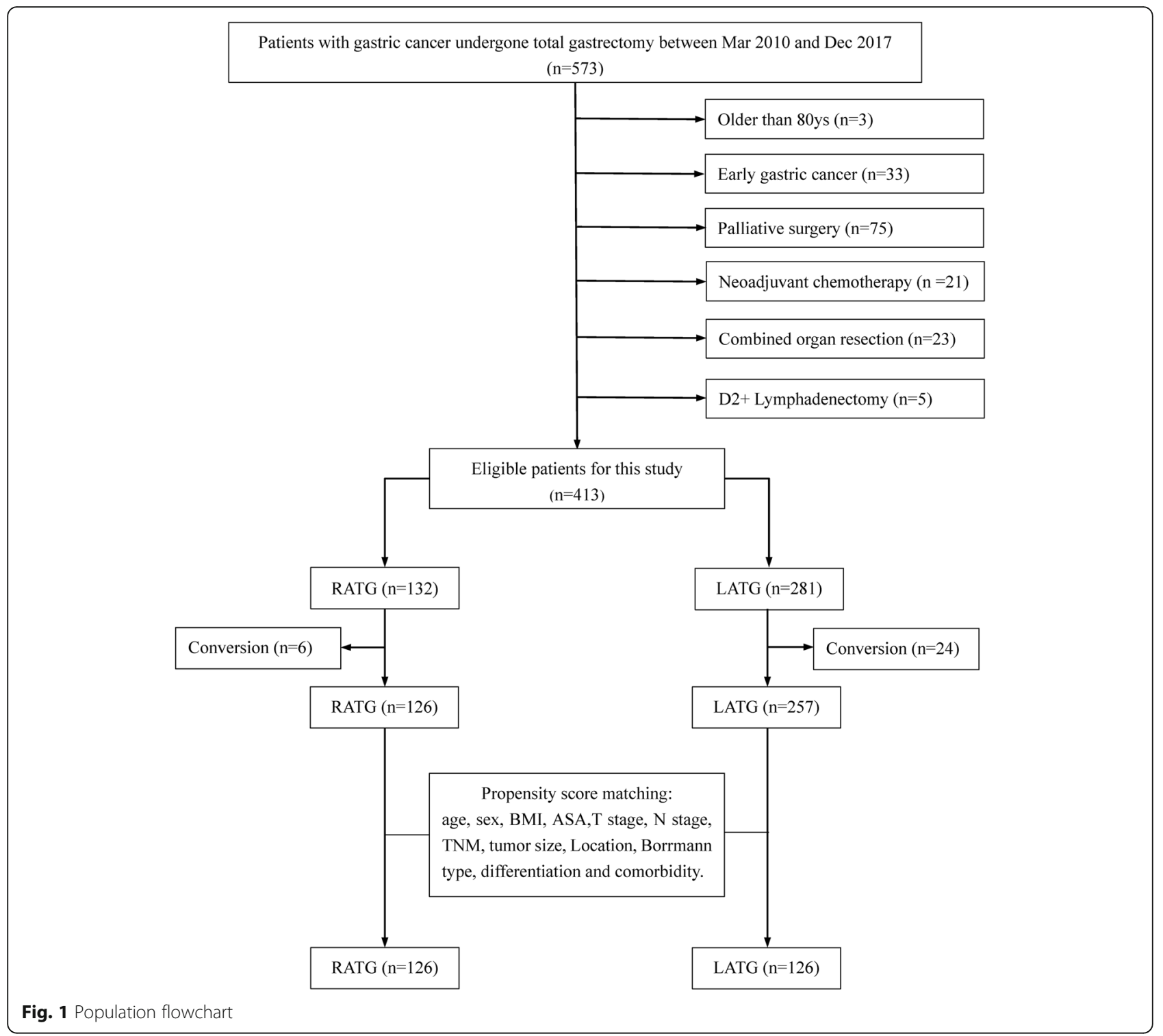

LATG group when the tumour was located at the esophagogastric junction, while there was no significant difference between the two groups when the tumour was located at the non-esophagogastric junction. Subgroup analysis of tumour size measured by resection specimen suggested that the RATG group had a longer operation time and more N2 tier RLNs compared with the LATG group in patients with tumour sizes smaller than $5 \mathrm{~cm}$, while there was no significant difference between the two groups in patients with tumour sizes larger than $5 \mathrm{~cm}$ (Table 5). RATG had less intraoperative bleeding and more N2 tier RLNs compared with the LATG group in patients with age younger than 65 years old, while there was no significant difference between them in patients older than 65 years old (Table 6).

\section{Discussion}

It is well known that total gastrectomy combined with complete D2 lymphadenectomy and esophagojejunostomy is a technically difficult procedure compared to distal gastrectomy to dissect more lymph nodes [12]. Nonetheless, we described our experience with LATG in the treatment of AGC in 2013, which indicated that LATG was a feasible and safe alternative to standard open gastric resection with similar short-term and longterm results [29]. In regard to RATG, Yoon et al. and Son et al. both reported comparable short-term surgical and oncologic outcomes between RATG and LATG, yet EGC patients accounted for a large percentage of the population in their studies [22, 23]. Ye's study, which included a total of 205 patients with AGC who underwent RATG or LATG, reported that RATG had a longer 
Table 1 Clinicopathological characteristics

\begin{tabular}{|c|c|c|c|c|c|c|}
\hline \multirow[t]{2}{*}{ Variables } & \multicolumn{3}{|l|}{ All Patients } & \multicolumn{3}{|c|}{ Patients after PSM } \\
\hline & $\operatorname{RATG}(n=126)$ & $\operatorname{LATG}(n=257)$ & $p$ & $\operatorname{RATG}(n=126)$ & $\operatorname{LATG}(n=126)$ & $p$ \\
\hline Age, year (mean $\pm S D)$ & $60.33 \pm 8.94$ & $58.26 \pm 10.41$ & 0.051 & $60.33 \pm 8.94$ & $60.78 \pm 9.05$ & 0.690 \\
\hline Sex (male/female) & $105 / 21$ & $197 / 60$ & 0.133 & $105 / 21$ & $100 / 26$ & 0.419 \\
\hline Height, cm (mean \pm SD) & $163.52 \pm 6.58$ & $162.74 \pm 7.25$ & 0.304 & $163.52 \pm 6.58$ & $162.79 \pm 7.91$ & 0.422 \\
\hline Weight, Kg (mean \pm SD) & $59.21 \pm 8.37$ & $59.63 \pm 9.46$ & 0.667 & $59.21 \pm 8.37$ & $58.84 \pm 9.70$ & 0.745 \\
\hline $\mathrm{BMl}, \mathrm{Kg} / \mathrm{m}^{2}($ mean $\pm \mathrm{SD})$ & $22.10 \pm 2.48$ & $22.46 \pm 2.93$ & 0.200 & $22.10 \pm 2.48$ & $22.13 \pm 2.84$ & 0.929 \\
\hline ASA $(I /|| / \mid I I)$ & $87 / 36 / 3$ & $185 / 68 / 4$ & 0.529 & $87 / 36 / 3$ & $94 / 30 / 2$ & 0.320 \\
\hline Tumor size, $\mathrm{cm}$ (mean $\pm \mathrm{SD}$ ) & $4.62 \pm 2.22$ & $4.55 \pm 2.28$ & 0.759 & $4.62 \pm 2.22$ & $4.40 \pm 2.35$ & 0.446 \\
\hline Tumor location & & & 0.398 & & & 0.661 \\
\hline Siewert type II & 28 & 61 & & 28 & 28 & \\
\hline Siewert type III & 30 & 69 & & 30 & 33 & \\
\hline Body & 68 & 127 & & 68 & 65 & \\
\hline Borrmann type & & & 0.076 & & & 0.785 \\
\hline |/II/III/IV & $3 / 11 / 100 / 12$ & $11 / 27 / 207 / 12$ & & $3 / 11 / 100 / 12$ & $2 / 10 / 106 / 8$ & \\
\hline Depth of infiltration (T) & & & 0.023 & & & 0.796 \\
\hline $\mathrm{T} 2$ & 7 & 36 & & 7 & 9 & \\
\hline $\mathrm{T} 3$ & 2 & 3 & & 2 & 1 & \\
\hline $\mathrm{T} 4 \mathrm{a}$ & 117 & 218 & & 117 & 116 & \\
\hline Nodal status (N) & & & 0.483 & & & 0.841 \\
\hline No & 29 & 64 & & 29 & 30 & \\
\hline N1 & 29 & 45 & & 29 & 25 & \\
\hline N2 & 27 & 43 & & 27 & 25 & \\
\hline N3a & 21 & 61 & & 21 & 29 & \\
\hline N3b & 20 & 44 & & 20 & 17 & \\
\hline TNM stage & & & 0.814 & & & 0.803 \\
\hline $\mathrm{IB}$ & 3 & 23 & & 3 & 3 & \\
\hline$\| \mathrm{A}$ & 6 & 7 & & 6 & 0 & \\
\hline$\| B$ & 24 & 44 & & 24 & 27 & \\
\hline IIIA & 52 & 81 & & 52 & 45 & \\
\hline$\| \mathrm{II}$ & 21 & 58 & & 21 & 31 & \\
\hline $\mathrm{IIIC}$ & 20 & 44 & & 20 & 10 & \\
\hline Differentiation & & & 0.006 & & & 0.534 \\
\hline $\mathrm{G} 1 / \mathrm{G} 2 / \mathrm{G} 3$ & 0/28/98 & $1 / 92 / 164$ & & 0/28/98 & $0 / 24 / 102$ & \\
\hline Comorbidities (0/1/2/3) & $91 / 23 / 6 / 6$ & $174 / 52 / 25 / 6$ & 0.385 & $91 / 23 / 6 / 6$ & $91 / 22 / 11 / 2$ & 0.983 \\
\hline Abdominal surgery history $(\mathrm{Y} / \mathrm{N})$ & $5 / 121$ & $26 / 231$ & 0.038 & $5 / 121$ & $13 / 113$ & 0.050 \\
\hline
\end{tabular}

RATG Robotic-assisted total gastrectomy, LATG Laparoscopic-assisted total gastrectomy, PSM Propensity Score Matching, SD Standard Deviation, BMI body mass index, ASA American Society of Anesthesiologists, TNM tumor-node-metastasis, G1/G2/G3 High/Middle/Low or Mucus differentiation, Comorbidities (0/1/2/3) no/ one/two/three comorbidities, $Y$ Yes, $N$ No.

operation time, more RLNs, and less operative blood loss and volume of abdominal drainage compared to LATG, and the complication rate was comparable $(7.5 \%$ vs. $9.1 \%, p=0.915,24]$. To the best of our knowledge, our study is the first to report the short-term outcomes of RATG compared with LATG for AGC using the PSM method to reduce bias.
Generally, robotic gastrectomy is known to have some advantages over laparoscopic surgery in reducing perioperative bleeding $[17,24,30]$. In our study, we also concluded that robotic surgery can reduce intraoperative bleeding compared to laparoscopic surgery after PSM $(154.37 \pm 89.68$ vs. $183.77 \pm 95.39$ $\mathrm{ml}, p=0.004)$. Although the mean difference of 
Table 2 Comparison of surgical outcomes and postoperative recovery

\begin{tabular}{|c|c|c|c|c|c|c|}
\hline \multirow[t]{2}{*}{ Variables } & \multicolumn{3}{|l|}{ All Patients } & \multicolumn{3}{|c|}{ Patients after PSM } \\
\hline & $\operatorname{RATG}(n=126)$ & $\operatorname{LATG}(n=257)$ & $p$ & $\operatorname{RATG}(n=126)$ & $\operatorname{LATG}(n=126)$ & $p$ \\
\hline Operation time, min (mean \pm SD) & $291.14 \pm 59.18$ & $270.27 \pm 49.41$ & 0.003 & $291.14 \pm 59.18$ & $270.34 \pm 52.22$ & 0.003 \\
\hline Bleeding, $\mathrm{ml}($ mean $\pm \mathrm{SD})$ & $154.37 \pm 89.68$ & $175.19 \pm 105.44$ & 0.028 & $154.37 \pm 89.68$ & $183.77 \pm 95.39$ & 0.004 \\
\hline Retrieved lymph nodes (mean \pm SD) & $34.90 \pm 13.05$ & $32.02 \pm 12.41$ & 0.037 & $34.90 \pm 13.05$ & $31.91 \pm 12.46$ & 0.065 \\
\hline $\mathrm{N} 1$ tier $($ mean $\pm \mathrm{SD})$ & $25.83 \pm 10.68$ & $24.41 \pm 10.09$ & 0.206 & $25.83 \pm 10.68$ & $24.36 \pm 10.00$ & 0.261 \\
\hline N2 tier (mean $\pm \mathrm{SD}$ ) & $9.07 \pm 5.34$ & $7.61 \pm 4.57$ & 0.007 & $9.07 \pm 5.34$ & $7.56 \pm 4.50$ & 0.016 \\
\hline Length of incision, $\mathrm{cm}$ (mean $\pm \mathrm{SD}$ ) & $6.32 \pm 1.58$ & $6.34 \pm 1.75$ & 0.546 & $6.32 \pm 1.58$ & $6.46 \pm 1.87$ & 0.914 \\
\hline Proximal margin, $\mathrm{cm}($ mean $\pm \mathrm{SD})$ & $3.55 \pm 1.69$ & $3.67 \pm 1.43$ & 0.488 & $3.55 \pm 1.69$ & $3.67 \pm 1.53$ & 0.553 \\
\hline Distal margin, $\mathrm{cm}($ mean $\pm \mathrm{SD})$ & $7.14 \pm 3.68$ & $7.59 \pm 3.79$ & 0.275 & $7.14 \pm 3.68$ & $7.72 \pm 3.83$ & 0.225 \\
\hline $\mathrm{R} 0 / \mathrm{R} 1$ & $116 / 10$ & $244 / 13$ & 0.265 & $116 / 10$ & $118 / 8$ & 0.625 \\
\hline Postoperative hospital stay, $\mathrm{d}$ (mean $\pm \mathrm{SD}$ ) & $9.62 \pm 2.86$ & $9.93 \pm 4.00$ & 0.430 & $9.62 \pm 2.86$ & $9.86 \pm 4.31$ & 0.606 \\
\hline
\end{tabular}

RATG Robotic-assisted total gastrectomy, LATG Laparoscopic-assisted total gastrectomy, PSM Propensity Score Matching, SD Standard Deviation, $R$ Residual disease(R classification)

approximately $30 \mathrm{~mL}$ of blood loss between the two minimally invasive groups may not provide much clinical benefit for every individual patient, this may show that the robot can operate more accurately to reduce bleeding. However, the present study demonstrated that the operative time of RATG was significantly longer than that of LATG after PSM, which was consistent with the findings of previous studies [22-24]. The docking time of robot arms, the time for arm change during clipping, and the lack of experience of the assistants may explain the longer operative time [22]. The docking time of robotic surgeries was between 20 and $60 \mathrm{~min}$, as reported in a meta-analysis [31]. Since all of our surgeons had performed robotic surgery (RG) for more than 30 cases, the docking time mainly accounted for the prolonged operating time. Hence, the extra time spent in our study (approximately $20 \mathrm{~min}$ ) for robotic surgery could be acceptable, as docking time was inevitable.

D2 lymphadenectomy is an indispensable process for the application of minimally invasive surgery for AGC [32]. The dissection of the N2 area is the most crucial part of lymphadenectomy. It has been reported that robotic surgery could retrieve more dissected lymph nodes, especially in the technically demanding N2 area, especially in the suprapancreatic area and splenic vessels [33]. In addition, Son et al. found that robotic spleenpreserving total gastrectomy could retrieve more LNs around splenic vessels and the hilum than laparoscopy, and they even compared each group and their metastases [23]. At the same time, the subgroup analysis of a meta-analysis revealed that the number of RLNs of RG was significantly higher than that of LG $(p=0.03,31]$. Our study shown that RATG can retrieve more N2 tier RLNs ( $p=0.007$ vs. $p=0.016)$ than LATG both before and after PSM. Nevertheless, the difference in RLNs between the two methods was not clinically significant after PSM. Moreover, the study by Shen et al., which included 23 robotic and 75 laparoscopic total gastrectomy procedures, reported that the RAG and LAG groups had no significant difference in the number of harvested lymph nodes [30]. Li et al. found in their stratified analysis of 92 patients after PSM that the average number of RLNs was not significantly different between robotic and laparoscopic total gastrectomy (30.6 vs. 32.0, $p=0.406,34]$. Therefore, it is still controversial whether robotic total gastrectomy can retrieve more lymph nodes. Thus further studies of robotic total gastrectomy, especially RCTs, should be conducted to focus on this issue.

Postoperative complications are an important factor to evaluate the safety and feasibility of a surgical procedure. We evaluated postoperative complications according to the Clavien-Dindo classification system, which is applicable in most parts of the world [25]. Previous studies have proven that the complication rate of laparoscopic total gastrectomy varies from 9.1 to $34.6 \%$ [14, 22-24, $34,35]$. In the current study, the complication rate of the RATG group was not significantly different from that of the LATG group before PSM (23.8\% vs. $29.2 \%$, $p=0.268)$ and after PSM (23.8\% vs. $28.6 \%, p=0.390)$. Not surprisingly, pulmonary complications obviously accounted for most of the complications in our study. Upper abdominal surgery combined with pneumoperitoneum and postoperative pain affect the activity of the diaphragm and lead to micro-atelectasis, which in turn causes pulmonary dysfunction. More importantly, total gastrectomy was an independent risk factor for pulmonary complications [36]. Moreover, anastomosis complications were considered to be one of the most serious 
Table 3 Postoperative morbidity and mortality

\begin{tabular}{|c|c|c|c|c|c|c|}
\hline \multirow[t]{2}{*}{ Variables } & \multicolumn{3}{|l|}{ All Patients } & \multicolumn{3}{|c|}{ Patients after PSM } \\
\hline & $\operatorname{RATG}(n=126)$ & $\operatorname{LATG}(n=257)$ & $p$ & $\operatorname{RATG}(n=126)$ & $\operatorname{LATG}(n=126)$ & $p$ \\
\hline Present/absent & 30/96 (23.8\%) & 75/182 (29.2\%) & 0.268 & 30/96 (23.8\%) & $36 / 90(28.6 \%)$ & 0.390 \\
\hline \multicolumn{7}{|l|}{ Clavien-Dindo Classification } \\
\hline । & $3(2.4 \%)$ & $11(4.3 \%)$ & 0.352 & $3(2.4 \%)$ & $7(5.6 \%)$ & 0.197 \\
\hline Wound problem & 2 & 5 & & 2 & 2 & \\
\hline Fever & 1 & 5 & & 1 & 3 & \\
\hline Cardiac dysfunction & 0 & 2 & & 0 & 2 & \\
\hline Diarrhea & 0 & 2 & & 0 & 1 & \\
\hline Chylous leakage & 0 & 1 & & 0 & 1 & \\
\hline$\|$ & $20(15.9 \%)$ & $43(16.7 \%)$ & 0.831 & $20(15.9 \%)$ & $22(17.5 \%)$ & 0.735 \\
\hline Fever & 5 & 4 & & 5 & 3 & \\
\hline Wound infection & 0 & 1 & & 0 & 1 & \\
\hline Intra-abdominal infection & 2 & 7 & & 2 & 4 & \\
\hline Intestinal obstruction & 1 & 0 & & 1 & 0 & \\
\hline Catheter infections & 4 & 1 & & 4 & 1 & \\
\hline Pulmonary infection & 8 & 21 & & 8 & 11 & \\
\hline Pulmonary atelectasis & 0 & 4 & & 0 & 0 & \\
\hline Pleural effusion & 3 & 10 & & 3 & 4 & \\
\hline Anastomotic leakage & 2 & 6 & & 2 & 1 & \\
\hline Anastomotic stenosis & 2 & 1 & & 2 & 0 & \\
\hline Intra-abdominal bleeding & 1 & 2 & & 1 & 2 & \\
\hline Duodenal stump leakage & 0 & 2 & & 0 & 1 & \\
\hline Cardiac dysfunction & 0 & 2 & & 0 & 1 & \\
\hline Illa & $2(1.6 \%)$ & $9(3.5 \%)$ & 0.466 & $2(1.6 \%)$ & $3(2.4 \%)$ & 1.000 \\
\hline Wound problem & 0 & 2 & & 0 & 1 & \\
\hline Duodenal stump leakage & 1 & 0 & & 1 & 0 & \\
\hline Anastomotic leakage & 0 & 3 & & 0 & 1 & \\
\hline Pleural effusion & 1 & 6 & & 1 & 2 & \\
\hline Pyothorax & 0 & 1 & & 0 & 0 & \\
\hline Intra-abdominal infection & 0 & 5 & & 0 & 2 & \\
\hline IIlb & $2(1.6 \%)$ & $4(1.6 \%)$ & 1.000 & $2(1.6 \%)$ & $0(0 \%)$ & 0.478 \\
\hline Intra-abdominal bleeding & 1 & 1 & & 1 & 0 & \\
\hline Anastomotic bleeding & 0 & 1 & & 0 & 0 & \\
\hline Duodenal stump leakage & 0 & 1 & & 0 & 0 & \\
\hline Anastomotic leakage & 1 & 1 & & 1 & 0 & \\
\hline IVa & $2(1.6 \%)$ & $4(1.6 \%)$ & 1.000 & $2(1.6 \%)$ & $2(1.6 \%)$ & 1.000 \\
\hline Respiratory failure & 2 & 3 & & 2 & 1 & \\
\hline Cardiac failure & 0 & 1 & & 0 & 1 & \\
\hline $\mathrm{IVb}$ & $0(0 \%)$ & $3(1.2 \%)$ & 0.554 & $0(0 \%)$ & $1(0.8 \%)$ & 1.000 \\
\hline MODS & 0 & 3 & & 0 & 1 & \\
\hline V & $1(0.8 \%)$ & $1(0.4 \%)$ & 0.550 & $1(0.8 \%)$ & $1(0.8 \%)$ & 1.000 \\
\hline Clavien-Dindo grade $\geq \| I l a$ & $7(5.6 \%)$ & $21(8.2 \%)$ & 0.356 & $7(5.6 \%)$ & $7(5.6 \%)$ & 1.000 \\
\hline Mortality & $1(0.8 \%)$ & $1(0.4 \%)$ & 0.550 & $1(0.8 \%)$ & $1(0.8 \%)$ & 1.000 \\
\hline
\end{tabular}

RATG Robotic-assisted total gastrectomy, LATG Laparoscopic-assisted total gastrectomy, PSM Propensity Score Matching, MODS Multiple Organ Dysfunction Syndrome 
Table 4 Comparison of the 2 surgical methods between different tumor location after PSM

\begin{tabular}{|c|c|c|c|c|c|c|}
\hline & Location EGJ & & & Location non-EG & & \\
\hline & $\operatorname{RATG}(n=58)$ & $\operatorname{LATG}(n=61)$ & $p$ & $\operatorname{RATG}(n=68)$ & $\operatorname{LATG}(n=65)$ & $p$ \\
\hline Age & $61.64 \pm 8.57$ & $62.41 \pm 7.80$ & 0.608 & $59.21 \pm 9.16$ & $59.25 \pm 9.89$ & 0.981 \\
\hline Sex (male/female) & $50 / 8$ & $51 / 10$ & 0.692 & $55 / 13$ & $49 / 16$ & 0.443 \\
\hline $\mathrm{BMI}\left(\mathrm{kg} / \mathrm{m}^{2}\right)$ & $22.90 \pm 2.38$ & $22.45 \pm 2.82$ & 0.344 & $21.41 \pm 2.37$ & $21.82 \pm 2.84$ & 0.359 \\
\hline Tumor size $(\mathrm{cm})$ & $3.66 \pm 1.53$ & $4.10 \pm 1.51$ & 0.121 & $5.44 \pm 2.39$ & $4.69 \pm 2.91$ & 0.106 \\
\hline TNM (IB/IIA/IB/IIIA/IIB/IIIC) & $2 / 1 / 12 / 27 / 11 / 5$ & $1 / 1 / 10 / 29 / 12 / 8$ & 0.350 & $1 / 5 / 12 / 25 / 10 / 15$ & $7 / 0 / 12 / 21 / 16 / 9$ & 0.611 \\
\hline Comorbidities (present/absent) & $18 / 40$ & $11 / 50$ & 0.099 & $17 / 51$ & $24 / 41$ & 0.137 \\
\hline Operation time (min) & $287.98 \pm 51.97$ & $273.07 \pm 49.62$ & 0.113 & $293.84 \pm 64.95$ & $267.78 \pm 54.80$ & 0.014 \\
\hline Estimated blood loss (ml) & $134.66 \pm 58.83$ & $173.93 \pm 89.41$ & 0.011 & $171.18 \pm 106.95$ & $193.00 \pm 100.49$ & 0.085 \\
\hline No. of N2 tier & $8.79 \pm 4.86$ & $7.43 \pm 3.84$ & 0.091 & $9.31 \pm 5.75$ & $7.68 \pm 5.07$ & 0.085 \\
\hline No. of Retrieved lymph nodes & $35.43 \pm 13.38$ & $33.36 \pm 11.68$ & 0.184 & $34.44 \pm 12.84$ & $31.49 \pm 13.23$ & 0.194 \\
\hline R0/R1 & $52 / 6$ & $56 / 5$ & 0.686 & $64 / 4$ & $62 / 3$ & 1.000 \\
\hline Proximal margin $(\mathrm{cm})$ & $2.12 \pm 0.99$ & $2.58 \pm 1.08$ & 0.013 & $4.77 \pm 1.11$ & $4.69 \pm 1.14$ & 0.682 \\
\hline Postoperative complication (\%) & $18(31.0)$ & $15(24.6)$ & 0.433 & $12(17.6)$ & $17(26.2)$ & 0.235 \\
\hline Clavien-Dindo grade $\geq$ IIla (\%) & $5(8.6)$ & $1(1.6)$ & 0.187 & $2(2.9)$ & $6(9.2)$ & 0.246 \\
\hline Postoperative hospital stay (d) & $9.90 \pm 2.77$ & $9.31 \pm 1.85$ & 0.176 & $9.38 \pm 2.93$ & $10.37 \pm 5.71$ & 0.914 \\
\hline
\end{tabular}

RATG Robotic-assisted total gastrectomy, LATG Laparoscopic-assisted total gastrectomy, BMI body mass index, TNM tumor-node-metastasis, EGJ esophagogastric junction, $R$ Residual disease(R classification)

complications after TG and result in poorer quality of life, prolonged hospital stay, and increased surgeryrelated costs and mortality [37]. The Japanese National Clinical Database (NCD) of digestive surgery reported that the incidence of anastomotic leakage after total gastrectomy was $4.4 \%(881$ of 20,011$)$ in 2011 [38]. Of the 383 patients included in the analysis, 6 patients in the RATG group and 10 in the LATG group encountered anastomosis-related complications $(4.76 \%$ vs. $3.89 \%, p=0.689$ ). The ratio of anastomosis-related complications in the present study was similar with that in previous studies.

Table 5 Comparison of the 2 surgical methods between different tumor size after PSM

\begin{tabular}{|c|c|c|c|c|c|c|}
\hline & \multicolumn{3}{|l|}{ Size $\geq 5 \mathrm{~cm}$} & \multicolumn{3}{|l|}{ Size $<5 \mathrm{~cm}$} \\
\hline & $\operatorname{RATG}(n=56)$ & $\operatorname{LATG}(n=43)$ & $p$ & $\operatorname{RATG}(n=70)$ & $\operatorname{LATG}(n=83)$ & $p$ \\
\hline Age & $61.77 \pm 8.23$ & $60.47 \pm 8.09$ & 0.433 & $59.17 \pm 9.37$ & $60.94 \pm 9.55$ & 0.251 \\
\hline Sex (male/female) & $45 / 11$ & $34 / 9$ & 0.874 & $60 / 10$ & $66 / 17$ & 0.317 \\
\hline BMI $\left(\mathrm{kg} / \mathrm{m}^{2}\right)$ & $21.74 \pm 2.34$ & $22.52 \pm 3.20$ & 0.218 & $22.38 \pm 2.57$ & $21.92 \pm 2.62$ & 0.277 \\
\hline Tumor location (non-EGJ/EGJ) & $39 / 17$ & $23 / 20$ & 0.100 & $29 / 41$ & $41 / 42$ & 0.324 \\
\hline TNM (IB/IA/IIB/IIIA/IIB/\|C) & $3 / 2 / 8 / 20 / 11 / 12$ & 1/0/8/17/9/8 & 0.959 & 0/4/16/32/10/8 & 7/1/14/33/19/9 & 0.950 \\
\hline Comorbidities (present/absent) & $17 / 39$ & $13 / 30$ & 0.989 & $18 / 52$ & $22 / 61$ & 0.912 \\
\hline Operation time (min) & $287.46 \pm 56.87$ & $278.33 \pm 55.51$ & 0.425 & $294.09 \pm 61.20$ & $266.20 \pm 50.27$ & 0.002 \\
\hline Estimated blood loss (ml) & $159.82 \pm 75.14$ & $198.95 \pm 110.76$ & 0.132 & $150.00 \pm 100.13$ & $175.90 \pm 86.03$ & 0.087 \\
\hline No. of N2 tier & $8.64 \pm 4.63$ & $8.14 \pm 4.78$ & 0.599 & $9.41 \pm 5.86$ & $7.25 \pm 4.35$ & 0.010 \\
\hline No. of Retrieved lymph nodes & $36.70 \pm 13.18$ & $33.14 \pm 11.66$ & 0.165 & $33.46 \pm 12.86$ & $31.28 \pm 12.88$ & 0.298 \\
\hline R0/R1 & $53 / 3$ & $40 / 3$ & 1.000 & $63 / 7$ & $78 / 5$ & 0.362 \\
\hline Proximal margin (cm) & $3.96 \pm 1.62$ & $3.85 \pm 1.37$ & 0.708 & $3.21 \pm 1.69$ & $3.57 \pm 1.61$ & 0.179 \\
\hline Postoperative complication (\%) & $15(26.8)$ & $16(37.2)$ & 0.268 & $15(21.4)$ & $20(24.1)$ & 0.696 \\
\hline Clavien-Dindo grade $\geq \| \mathrm{ll}(\%)$ & $2(3.6)$ & $4(9.3)$ & 0.447 & $5(7.1)$ & $3(3.6)$ & 0.540 \\
\hline Postoperative hospital stay (d) & $9.61 \pm 1.99$ & $10.58 \pm 5.13$ & 0.951 & $9.63 \pm 3.41$ & $9.48 \pm 3.80$ & 0.804 \\
\hline
\end{tabular}


Table 6 Comparison of the 2 surgical methods between different age after PSM

\begin{tabular}{|c|c|c|c|c|c|c|}
\hline & Age $\geq 65 y s$ & & & Age $<65 y s$ & & \\
\hline & $\operatorname{RATG}(n=47)$ & $\operatorname{LATG}(n=44)$ & $p$ & $\operatorname{RATG}(n=79)$ & $\operatorname{LATG}(n=82)$ & $p$ \\
\hline Sex (male/female) & $42 / 5$ & $37 / 7$ & 0.458 & $63 / 16$ & $63 / 19$ & 0.654 \\
\hline BMI $\left(\mathrm{kg} / \mathrm{m}^{2}\right)$ & $22.54 \pm 2.69$ & $21.69 \pm 2.68$ & 0.137 & $21.83 \pm 2.32$ & $22.36 \pm 2.90$ & 0.214 \\
\hline Tumor location (non-EGJ/EGJ) & $20 / 27$ & $22 / 22$ & 0.476 & $48 / 31$ & $43 / 39$ & 0.287 \\
\hline Tumor size $(\mathrm{cm})$ & $4.39 \pm 2.05$ & $4.48 \pm 2.70$ & 0.868 & $4.76 \pm 2.31$ & $4.36 \pm 2.16$ & 0.263 \\
\hline TNM (IB/IIA/IB/IIIA/IIB/IIIC) & 2/3/4/17/11/10 & $4 / 1 / 6 / 15 / 11 / 7$ & 0.503 & $1 / 3 / 20 / 35 / 10 / 10$ & $4 / 0 / 16 / 35 / 17 / 10$ & 0.340 \\
\hline Comorbidities (present/absent) & $14 / 33$ & $18 / 26$ & 0.267 & $21 / 58$ & $17 / 65$ & 0.382 \\
\hline Operation time (min) & $291.70 \pm 71.98$ & $259.98 \pm 49.99$ & 0.017 & $290.81 \pm 50.55$ & $275.90 \pm 52.83$ & 0.069 \\
\hline Estimated blood loss (ml) & $161.81 \pm 94.15$ & $174.20 \pm 90.68$ & 0.524 & $149.94 \pm 87.23$ & $188.90 \pm 97.98$ & 0.037 \\
\hline No. of N2 tier & $9.19 \pm 6.45$ & $7.41 \pm 4.18$ & 0.124 & $9.00 \pm 4.61$ & $7.63 \pm 4.69$ & 0.012 \\
\hline No. of Retrieved lymph nodes & $34.79 \pm 13.33$ & $33.02 \pm 12.29$ & 0.514 & $34.96 \pm 12.96$ & $31.32 \pm 12.59$ & 0.072 \\
\hline $\mathrm{R} 0 / \mathrm{R} 1$ & $42 / 5$ & $39 / 5$ & 1.000 & $72 / 5$ & $79 / 3$ & 0.650 \\
\hline Proximal margin $(\mathrm{cm})$ & $3.22 \pm 1.57$ & $3.61 \pm 1.44$ & 0.221 & $3.74 \pm 1.74$ & $3.70 \pm 1.59$ & 0.870 \\
\hline Postoperative complication (\%) & $14(29.8)$ & $14(31.8)$ & 0.834 & $16(20.3)$ & $22(26.8)$ & 0.326 \\
\hline Clavien-Dindo grade $\geq$ IIla (\%) & $3(6.4)$ & $1(2.3)$ & 0.657 & $4(5.1)$ & $6(7.3)$ & 0.554 \\
\hline Postoperative hospital stay (d) & $9.79 \pm 2.81$ & $10.34 \pm 4.98$ & 0.512 & $9.52 \pm 2.92$ & $9.60 \pm 3.92$ & 0.885 \\
\hline
\end{tabular}

RATG Robotic-assisted total gastrectomy, LATG Laparoscopic-assisted total gastrectomy, BMI body mass index, TNM tumor-node-metastasis, EGJ esophagogastric junction, $R$ Residual disease(R classification)

Since total gastrectomy was the most common treatment choice for upper gastric cancer, which includes tumours in the proximal third of the stomach and EGJ [6-8], we conducted subgroup analysis according to tumour location. RATG for tumours located at the EGJ showed less intraoperative bleeding and comparable surgical outcomes compared to LATG. As we have mentioned the merits of robot, RG can manage the narrow anatomical fields such as the fundus of the stomach and esophageal hiatus more easily than LG, just as it can overcome the limitations of laparoscopic surgery in the pelvis during rectal surgery [39]. Despite not achieving much statistical significance, RATG have some advantages in dealing with EGJ cancer compared with LATG in our view combined with our limited surgical experience.

However, this study has several limitations. First, the results were based on a retrospective analysis from a single-clinic institution. Second, the present study lacks a detailed comparative analysis of the cost-effectiveness and gastrointestinal function recovery index between robotic and laparoscopic gastric surgery. Third, although the five surgeons who performed the surgeries received robotic surgery certification and were experienced in both minimally invasive surgeries, different surgeons can still cause some bias and further influence the results. Despite this study having some limitations, our findings provide evidence for minimally invasive surgery of total gastrectomy for AGC. Further well-designed studies, especially RCTs or prospective trials, are needed to assess the impact of RATG and LATG.

\section{Conclusion}

This retrospective study demonstrates that RATG is comparable to LATG in terms of short-term surgical outcomes. With longer operation time, less estimated blood loss, more N2 tier RLNs and similar complication rate after PSM, RATG is a safe, reliable and promising approach compared with LATG for the treatment of AGC. Well-designed and randomized controlled trials are needed to further compare RATG with LATG.

\section{Abbreviations}

AGC: Advanced gastric cancer; RATG: Robotic-assisted total gastrectomy; LATG: Laparoscopy-assisted total gastrectomy; PSM: Propensity score matching; RLNs: Retrieved lymph nodes; GC: Gastric cancer; TG: Total gastrectomy; LG: Laparoscopy gastrectomy; EGJ: Esophagogastric junction; EGC: Early gastric cancer; BMI: Body mass index; ASA: American Society of Anesthesiologists grade; TNM: Tumor-Node-Metastasis classification; AJCC: American Joint Committee on Cancer; LN: Lymph node; RG: Robotic gastrectomy; SD: Standard deviation; NCD: National Clinical Database

\footnotetext{
Acknowledgements

The authors thank Yan Wen and Xiao Luo for data collection and management and Xiaoqing Zhan for language editing.
}

\section{Authors' contributions}

CY and YS analyzed and interpreted the patient data and CY was a major contributor in writing the manuscript. SX and JC collected and collated data. YS, YZ, FQ, YH, and BT performed the surgeries, PY designed and been responsible for the article. All authors read and approved the final manuscript. 


\section{Funding}

Chongqing Science and Technology Commission, China (No. cstc2017shmsA10003). It offers financial support for the design of the study and collection, analysis, and interpretation of data and writing the manuscript and publication.

\section{Availability of data and materials}

The datasets used and analysed during the current study are available from the corresponding author upon reasonable request.

\section{Ethics approval and consent to participate}

This study was approved by the Ethics Committee of the First Affiliated Hospital of Army Medical University (Ethical number: KY201869) and the consent obtained from participants was written.

\section{Consent for publication}

Not applicable.

\section{Competing interests}

The authors declare that they have no competing interests.

Received: 26 October 2019 Accepted: 9 July 2020

Published online: 17 July 2020

\section{References}

1. Bray F, Ferlay J, Soerjomataram I, Siegel RL, Torre LA, Jemal A. Global cancer statistics 2018: GLOBOCAN estimates of incidence and mortality worldwide for 36 cancers in 185 countries. CA Cancer J Clin. 2018;68(6):394-424.

2. Torre LA, Siegel RL, Ward EM, Jemal A. Global Cancer incidence and mortality rates and trends--An update. Cancer Epidemiol Biomark Prev. 2016;25(1):16-27.

3. Siegel RL, Miller KD, Jemal A. Cancer statistics, 2017. CA Cancer J Clin. 2017; 67(1):7-30.

4. Liu K, Yang K, Zhang W, Chen X, Chen X, Zhang B, Chen Z, Chen J, Zhao Y, Zhou Z, et al. Changes of Esophagogastric Junctional adenocarcinoma and Gastroesophageal reflux disease among surgical patients during 1988-2012. Ann Surg. 2016:263(1):88-95.

5. Steevens J, Botterweck AA, Dirx MJ, van den Brandt PA, Schouten LJ. Trends in incidence of oesophageal and stomach cancer subtypes in Europe. Eur J Gastroenterol Hepatol. 2010;22(6):669-78.

6. Van Cutsem E, Sagaert X, Topal B, Haustermans K, Prenen H. Gastric cancer. Lancet. 2016:388(10060):2654-64.

7. Japanese Gastric Cancer Association. Japanese gastric cancer treatment guidelines 2014 (ver. 4). Gastric Cancer. 2017;20(1):1-19..

8. Ahmad SA, Xia BT, Bailey CE, Abbott DE, Helmink BA, Daly MC, Thota R, Schlegal C, Winer LK, Ahmad SA, et al. An update on gastric cancer. Curr Probl Surg. 2016;53(10):449-90.

9. Kitano S, Iso Y, Moriyama M, Sugimachi K. Laparoscopy-assisted Billroth I gastrectomy. Surg Laparosc Endosc. 1994;4(2):146-8.

10. Shi Y, Xu X, Zhao Y, Qian F, Tang B, Hao Y, Luo H, Chen J, Yu P. Short-term surgical outcomes of a randomized controlled trial comparing laparoscopic versus open gastrectomy with D2 lymph node dissection for advanced gastric cancer. Surg Endosc. 2018;32(5):2427-33.

11. Hu Y, Huang C, Sun Y, Su X, Cao H, Hu J, Xue Y, Suo J, Tao K, He X, et al. Morbidity and mortality of laparoscopic versus open D2 distal Gastrectomy for advanced gastric Cancer: a randomized controlled trial. J Clin Oncol. 2016;34(12):1350-7.

12. Brenkman HJF, Ruurda JP, Verhoeven RHA, van Hillegersberg R. Safety and feasibility of minimally invasive gastrectomy during the early introduction in the Netherlands: short-term oncological outcomes comparable to open gastrectomy. Gastric Cancer. 2017;20(5):853-60.

13. Son SY, Shin DJ, Park YS, Oo AM, Jung DH, Lee CM, Ahn SH, Park DJ, Kim $\mathrm{HH}$. Spleen-preserving lymphadenectomy versus splenectomy in laparoscopic total gastrectomy for advanced gastric cancer. Surg Oncol. 2017;26(2):207-11.

14. Wang W-J, Li H-T, Chen P, Yu J-P, Jiao Z-Y, Han X-P, Su L, Tao R-Y, Xu L, Kong $Y-L$, et al. A propensity score-matched comparison of laparoscopic distal versus total gastrectomy for middle-third advanced gastric cancer. Int J Surg. 2018;60:194-203.

15. van Boxel Gl, Ruurda JP, van Hillegersberg R. Robotic-assisted gastrectomy for gastric cancer: a European perspective. Gastric Cancer. 2019;22(5):909-19.
16. Hashizume M, Shimada M, Tomikawa M, Ikeda Y, Takahashi I, Abe R, Koga F, Gotoh N, Konishi K, Maehara S, et al. Early experiences of endoscopic procedures in general surgery assisted by a computer-enhanced surgical system. Surg Endosc. 2002;16(8):1187-91.

17. Junfeng Z, Yan S, Bo T, Yingxue H, Dongzhu Z, Yongliang Z, Feng Q, Peiwu $Y$. Robotic gastrectomy versus laparoscopic gastrectomy for gastric cancer: comparison of surgical performance and short-term outcomes. Surg Endosc. 2014;28(6):1779-87.

18. Kim HI, Han SU, Yang HK, Kim YW, Lee HJ, Ryu KW, Park JM, An JY, Kim MC, Park S, et al. Multicenter prospective comparative study of robotic versus laparoscopic Gastrectomy for gastric adenocarcinoma. Ann Surg. 2016; 263(1):103-9.

19. Coratti A, Fernandes E, Lombardi A, Di Marino M, Annecchiarico M, Felicioni L, Giulianotti PC. Robot-assisted surgery for gastric carcinoma: five years follow-up and beyond: a single western center experience and long-term oncological outcomes. Eur J Surg Oncol. 2015;41(8):1106-13.

20. Hyun $\mathrm{MH}$, Lee $\mathrm{CH}$, Kim HJ, Tong Y, Park SS. Systematic review and meta-analysis of robotic surgery compared with conventional laparoscopic and open resections for gastric carcinoma. Br J Surg. 2013; 100(12):1566-78.

21. Uyama I, Suda K, Nakauchi M, Kinoshita T, Noshiro H, Takiguchi S, Ehara K, Obama K, Kuwabara S, Okabe H, et al. Clinical advantages of robotic gastrectomy for clinical stage I/II gastric cancer: a multi-institutional prospective single-arm study. Gastric Cancer. 2019;22(2):377-85.

22. Yoon HM, Kim Y-W, Lee JH, Ryu KW, Eom BW, Park JY, Choi IJ, Kim CG, Lee JY, Cho SJ, et al. Robot-assisted total gastrectomy is comparable with laparoscopically assisted total gastrectomy for early gastric cancer. Surg Endosc. 2012;26(5):1377-81.

23. Son T, Lee JH, Kim YM, Kim HI, Noh SH, Hyung WJ. Robotic spleenpreserving total gastrectomy for gastric cancer: comparison with conventional laparoscopic procedure. Surg Endosc. 2014;28(9):2606-15.

24. Ye SP, Shi J, Liu DN, Jiang QG, Lei X, Qiu H, Li TY. Robotic-assisted versus conventional laparoscopic-assisted total gastrectomy with D2 lymphadenectomy for advanced gastric cancer: short-term outcomes at a mono-institution. BMC Surg. 2019;19(1):86.

25. Dindo D, Demartines N, Clavien P-A. Classification of surgical complications: a new proposal with evaluation in a cohort of 6336 patients and results of a survey. Ann Surg. 2004;240(2):205-13.

26. Clavien PA, Barkun J, de Oliveira ML, Vauthey JN, Dindo D, Schulick RD, de Santibanes E, Pekolj J, Slankamenac K, Bassi C, et al. The Clavien-Dindo classification of surgical complications: five-year experience. Ann Surg. 2009; 250(2):187-96.

27. Amin MB, Edge SB, Gfeene FL, Byrd DR. AJCC Canncer staging manual (eighth edition). New York: Springer; 2017.

28. Japanese Gastric Cancer Association. Japanese gastric cancer treatment guidelines 2010 (ver. 3). Gastric Cancer. 2011;14(2):113-23.

29. Bo T, Peiwu Y, Feng Q, Yongliang Z, Yan S, Yingxue H, Huaxing L. Laparoscopy-assisted vs. open total gastrectomy for advanced gastric cancer: long-term outcomes and technical aspects of a case-control study. J Gastrointest Surg. 2013;17(7):1202-8.

30. Shen W, Xi H, Wei B, Cui J, Bian S, Zhang K, Wang N, Huang X, Chen L. Robotic versus laparoscopic gastrectomy for gastric cancer: comparison of short-term surgical outcomes. Surg Endosc. 2016;30(2):574-80.

31. Chen K, Pan Y, Zhang B, Maher H, Wang XF, Cai XJ. Robotic versus laparoscopic Gastrectomy for gastric cancer: a systematic review and updated meta-analysis. BMC Surg. 2017;17(1):93.

32. Song J, Oh SJ, Kang WH, Hyung WJ, Choi SH, Noh SH. Robot-assisted gastrectomy with lymph node dissection for gastric cancer: lessons learned from an initial 100 consecutive procedures. Ann Surg. 2009;249(6):927-32.

33. Kim YW, Reim D, Park JY, Eom BW, Kook MC, Ryu KW, Yoon HM. Role of robot-assisted distal gastrectomy compared to laparoscopy-assisted distal gastrectomy in suprapancreatic nodal dissection for gastric cancer. Surg Endosc. 2016;30(4):1547-52.

34. Li Z, Li J, Li B, Bai B, Liu Y, Lian B, Zhao Q. Robotic versus laparoscopic gastrectomy with D2 lymph node dissection for advanced gastric cancer: a propensity score-matched analysis. Cancer Manag Res. 2018;10:705-14.

35. Kodera Y, Yoshida K, Kumamaru H, Kakeji Y, Hiki N, Etoh T, Honda M, Miyata H, Yamashita $Y$, Seto $Y$, et al. Introducing laparoscopic total gastrectomy for gastric cancer in general practice: a retrospective cohort study based on a nationwide registry database in Japan. Gastric Cancer. 2019;22(1):202-13. 
36. Ntutumu R, Liu H, Zhen L, Hu YF, Mou TY, Lin T, I BA, Yu J, Li GX. Risk factors for pulmonary complications following laparoscopic gastrectomy: a single-center study. Medicine (Baltimore). 2016;95(32):e4567.

37. Huang Q, Zhong J, Yang T, Li J, Luo K, Zheng Y, Yang H, Fu J. Impacts of anastomotic complications on the health-related quality of life after esophagectomy. J Surg Oncol. 2015;111(4):365-70.

38. Watanabe M, Miyata H, Gotoh M, Baba H, Kimura W, Tomita N, Nakagoe T, Shimada M, Kitagawa Y, Sugihara K, et al. Total gastrectomy risk model: data from 20,011 Japanese patients in a nationwide internet-based database. Ann Surg. 2014;260(6):1034-9.

39. Staderini F, Foppa C, Minuzzo A, Badii B, Qirici E, Trallori G, Mallardi B, Lami G, Macri G, Bonanomi A, et al. Robotic rectal surgery: state of the art. World J Gastrointest Oncol. 2016;8(11):757-71.

\section{Publisher's Note}

Springer Nature remains neutral with regard to jurisdictional claims in published maps and institutional affiliations.

Ready to submit your research? Choose BMC and benefit from:

- fast, convenient online submission

- thorough peer review by experienced researchers in your field

- rapid publication on acceptance

- support for research data, including large and complex data types

- gold Open Access which fosters wider collaboration and increased citations

- maximum visibility for your research: over $100 \mathrm{M}$ website views per year

At $B M C$, research is always in progress.

Learn more biomedcentral.com/submissions 